\title{
Colonization history and population genetic structure of Eichhornia paniculata in Jamaica
}

\author{
BRIAN C. HUSBAND \& SPENCER C. H. BARRETT \\ Department of Botany, University of Toronto, Toronto, Ontario M5S 3B2, Canada
}

\begin{abstract}
A study of variation at 27 isozyme loci in 12 Jamaican populations of Eichhornia paniculata (Pontederiaceae) was undertaken to examine the history and genetic consequences of island colonization. Population genetic theory predicts that island populations should be less variable relative to their sources, owing to founder effects and genetic drift. Populations were significantly less heterozygous $\left(H_{o}\right)$ with fewer polymorphic loci $(P)$ and alleles per polymorphic locus $\left(N_{a}\right)$ than previously reported for populations in northeastern Brazil. Populations contained small numbers of multilocus genotypes with one or two usually dominating. Four out of six populations exhibited moderate to high levels of gametic disequilibrium, a pattern expected from interactions between inbreeding and drift in colonizing populations. Estimates of outcrossing rate in eight populations averaged $t=0.116$ (range: $0.00-0.22$ ).

Seventy per cent of the total genetic diversity in Jamaica were distributed among populations. Marked differentiation at six polymorphic loci was evident between populations from the west and east-central parts of the island. Unique alleles at three loci were restricted to western populations. Spatial autocorrelation analysis of polymorphic loci confirmed that allelic diversity was nonrandomly distributed among populations. Spatial patterns at three loci were congruent, with each locus showing a replacement of alternate alleles in the same area. The results are consistent with a hypothesis of multiple colonization, with western populations of E. paniculata originating separately from the remaining populations on the island.
\end{abstract}

Keywords: colonization, Eichhornia paniculata, genetic drift, island populations, mating systems, population genetic structure.

\section{Introduction}

Historical processes are important determinants of geographical variation, particularly in hermaphrodite organisms capable of self-fertilization. Inbreeding tends to preserve multilocus associations established through stochastic processes such as founder events and genetic drift (Golding \& Strobeck, 1980; Brown, 1983). Self-fertilizing plants, with well-developed colonizing abilities and broad distributions, often show marked genetic differentiation in different parts of their geographical range. This effect is particularly likely in species with discontinuous distributions resulting from long distance dispersal (Barrett \& Husband, 1990a). Restricted recombination and a lack of recurrent migration from source populations aids in maintaining the integrity of founding genotypes. This can lead to distinctive patterns of genetic variation in introduced populations. Attempts at reconstructing the history of colonization have been particularly successful in inbreeding plants because of their propensity to form multilocus associations (Allard et al., 1972; Moran \& Marshall, 1978; Barrett \& Richardson, 1986; Golenberg, 1989; Novak \& Mack, 1989 and unpublished).

The geographical distribution of the tristylous, emergent, aquatic Eichhornia paniculata (Pontederiaceae) is markedly disjunct. Populations occur in ditches and ephemeral pools throughout northeastern Brazil, on the Caribbean islands of Jamaica and Cuba, and from single isolated localities in western Brazil, Ecuador and Nicaragua. The occurrence of three style morphs and related tristylous taxa in northeastern Brazil suggests that $E$. paniculata may have originated in lowland tropical South America (Barrett, 1985, 1988). Based on this supposition, the Caribbean is probably a derived centre for $E$. paniculata, although the source and time of colonization is unknown. Since the founding and establishment of populations on Caribbean islands may have involved infrequent and long-distance dispersal, studies of variation in the region can provide insights into the history and genetic 
consequences of colonization and establishment in a restricted geographical area.

In an earlier study of isozyme variation in $E$. paniculata, Glover \& Barrett (1987) found that Jamaican populations were genetically depauperate in comparison with populations from a comparable area in northeastern Brazil. They suggested that differences in genetic diversity between the regions were the result of genetic bottleneck(s) associated with long distance colonization and the predominant self-fertilization of island populations. Their study involved a sample of five Jamaican populations from the central region of the island. More recently, we have undertaken more extensive sampling from throughout the island to extend our knowledge of the organization of genetic variability, mating systems and colonization history of E. paniculata in Jamaica. Here, we (1) examine the partitioning of genetic diversity at isozyme loci within and among populations, (2) estimate outcrossing rates $(t)$, patterns of inbreeding and levels of gametic disequilibrium between isozyme loci, and (3) investigate spatial patterns of genetic variation among populations, using spatial autocorrelation techniques. Results from these analyses are used to infer patterns of colonization and the historical relationships of populations in Jamaica.

\section{Materials and methods}

\section{Sampling}

In January 1987, 12 populations of Eichhornia paniculata were sampled from throughout the range of the species in Jamaica. Open-pollinated seed families were collected in each population. Since plants flower more or less synchronously, a single random collection of families was sampled. Seeds were stored dry at room temperature until used for isozyme analysis. Seeds from several capsules, for each of five to 25 maternal plants from each population, were germinated on moist soil for electrophoresis. Where possible the number of seedlings was divided equally among maternal plants sampled from each population. The number of maternal plants in each population was limited by population size and germination levels. Since most populations were small $(<100)$, the sample of maternal families in each population comprised a complete sample or one large enough to represent adequately the populationlevel variability expected for a predominantly selffertilizing species. Glasshouse experiments indicate no significant differences among Jamaican populations in germination or survivorship between selfed and outcrossed progeny (Toppings, 1989).

\section{Electrophoretic methods}

Genetic variability at 27 isozyme loci was determined using horizontal starch gel electrophoresis. Flower buds (three to five) were crushed in an extract buffer, absorbed onto filter-paper wicks and inserted into 11 per cent starch gels. Running conditions and gel buffer systems used were previously described by Glover \& Barrett (1987). Individual genotypes were scored at isozyme loci for 13 enzyme systems: diaphorase (DIA), glutamate dehydrogenase (GDH), isocitric dehydrogenase (IDH), peroxidase (PER), 6-phosphogluconate dehydrogenase (6-PGD), shikimic dehydrogenase (SKDH), aspartate aminotransferase (AAT), phosphoglucomutase (PGM), acid phosphatase (ACP), phosphoglucomutase isomerase (PGI), triose phosphate isomerase (TPI), malate dehydrogenase $(\mathrm{MDH})$, and aconitase $(\mathrm{ACO})$. The staining recipe for TPI is given in Soltis et al. (1983); all others are from Glover \& Barrett (1987). Loci are numbered sequentially, starting with those coding for the most anodally migrating isozymes. Alleles coding for allozymes are identified in a similar manner, but with letters.

\section{Analysis of isozyme data}

Isozyme variation for each population was measured using standard genetic parameters including $N_{a}$, the mean number of alleles per polymorphic locus (when the frequency of the least common allele is $>0.05), P$, the percentage of loci that are polymorphic (where a locus is polymorphic when the frequency of the most common allele is $<0.95)$ and $H_{o}$, the observed frequency of heterozygotes, averaged over all loci. Pairwise gametic disequilibrium values $\left(D_{A B}\right)$ were estimated for the six populations of E. paniculata with two or more polymorphic loci (J17, J19, J22, J24, J25, J27). Disequilibrium values and standard deviations (not shown) were calculated from two-locus genotype frequencies (Weir \& Cockerham, 1989).

Multilocus estimates of outcrossing rate $(t)$, for the eight populations with polymorphic isozyme loci were calculated using the method of Ritland \& Jain (1981) and Ritland (1989). Maternal genotypes were inferred from progeny arrays using the method of Brown \& Allard (1970). The standard error for each population estimate of $t$ was calculated by bootstrapping and the goodness of fit of the observed genotype frequencies to the model was tested using a chi-squared test with 1 and 9 degrees of freedom for diallelic and triallelic loci, respectively.

To examine population genetic structure, allele frequencies for each polymorphic locus were com- 
pared among populations using a chi-squared contingency test. Overall significance of each of the simultaneous tests was determined using the sequential Bonferroni technique (Holm, 1979). To examine genetic differentiation among populations, Nei's $G_{S T}$, defined as the ratio of interpopulation gene diversity $\left(D_{S T}\right)$ to total gene diversity $\left(H_{T}: \mathrm{Nei}, 1973,1975\right)$ was estimated. In addition, gene correlations measured by Wright's $F$ statistics (Wright, 1951) were also estimated using the analysis of variance approach of Weir \& Cockerham (1984) where $F$ is the correlation of alleles within individuals in relation to all populations, $\phi$, the correlation of alleles from different individuals in the same population and $f$, the correlation of alleles within individuals, within populations. Variances for each estimate were derived by jack-knifing over populations. Cockerham $(1969,1973)$ demonstrated that these parameters are related to Wright's $F$ statistics as: $F=F_{I T}, \phi=F_{S T}$, and $f=F_{I S}$. While gene diversity and gene correlation parameters are related $\left[G_{S T}\right.$ is a weighted mean of $F_{S T}$ over all alleles, Takahata \& Nei (1984)], both $G_{S T}$ and $\phi\left(F_{S T}\right)$ are presented to enable comparisons with other published estimates.

To examine the spatial patterns of genetic variation among populations in Jamaica, six polymorphic isozyme loci were analysed using spatial autocorrelation methods. These techniques have previously been described (Sokal \& Oden, 1978; Sokal, 1979; Clifford \& Ord, 1973) and applied to allele frequency data (Sokal \& Menozzi, 1982; Barbujani, 1987; Sokal et al., 1987). Spatial patterns at each polymorphic locus were examined using estimates of Moran's autocorrelation coefficient (I; Sokal \& Oden, 1978). Connections between populations were established using Gabriel criteria (Gabriel \& Sokal, 1969), where two populations are connected if no other population lies on or within the circle whose diameter is the distance between them. Since populations are distributed in a roughly linear fashion across the length of the island, the method resulted in 13 connections among the 12 populations. Autocorrelation coefficients were then calculated based on all pairs of connected populations within each of five distance classes. Moran's I was compared to expectations under random patterns of variation using a standard normal deviate test (Sokal \& Oden, 1978). The distance classes were chosen to maximize the number of classes and population pairs and ranged from 10 to 14 pairs in each of five distance classes. The autocorrelation coefficient for each locus, calculated as a function of distance, represents a spatial correlogram. Correlograms were calculated for alleles at each polymorphic locus. Since three alleles were recorded for $P G M-1$, autocorrelation analysis was conducted on two, as they varied nearly independently. To compare spatial patterns produced by different loci, product-moment correlations were calculated between frequencies for all pairs of alleles, over the 12 localities (referred to as allele frequency surfaces, hereafter).

Spatial patterns were summarized by calculating the average autocorrelation coefficient for each distance class averaged over all loci. For comparison with previous studies, we also tested the association between geographic (Gabriel connection distance) and genetic distance (Nei, 1978) between populations using Kendall's non-parametric test. The significance of the test statistic $\left(K_{c}\right)$ is determined by generating a probability distribution based on 2000 permutations of the matrices (Dietz, 1983). Multilocus genetic identities $(I)$ and distances $(D ; \mathrm{Nei}, 1978)$ between all possible pairs of populations were calculated using all loci. Relationships between populations are presented as a dendrogram based on UPGMA clustering criteria.

\section{Results}

\section{Field observations}

The distribution of $E$. paniculata populations sampled in Jamaica is shown in Fig. 1. The aquatic habitats in which the species occur are largely restricted to the southern coastal plain and are absent from mountainous regions of the island and the rugged north coast. Populations ranged in size from five to 2000 individuals with a harmonic mean of 29.7 (Table 1). The three largest populations (J17, J18, J27) occurred as weeds of agricultural habitats (rice fields and sugar cane). The large size of these populations, in comparison to the remainder, was the result of open, fertile conditions in which they occurred.

Of the 12 populations sampled for style morph frequency, four were dimorphic for the long- and midstyled morphs (hereafter, $L$ and $M$ morphs) and the remainder were monomorphic for the $M$ morph. In three of the four dimorphic populations the $\mathrm{M}$ morph predominated (Fig. 1a). All individuals of the M morph in Jamaica possess 1-3 elongated short-level stamens resulting in automatic self-pollination of mid-level stigmas. Further details of the floral biology of these selfing variants are given in Barrett (1985).

\section{Population genetic structure}

Of the 27 isozyme loci surveyed, six ( 22 per cent) were polymorphic, with between zero and three loci $(0-11$ per cent) variable in any given population. Four of the 12 populations sampled contained no isozyme variability (Table 2). Polymorphic loci commonly exhibited large imbalances in the relative frequencies of alternate 

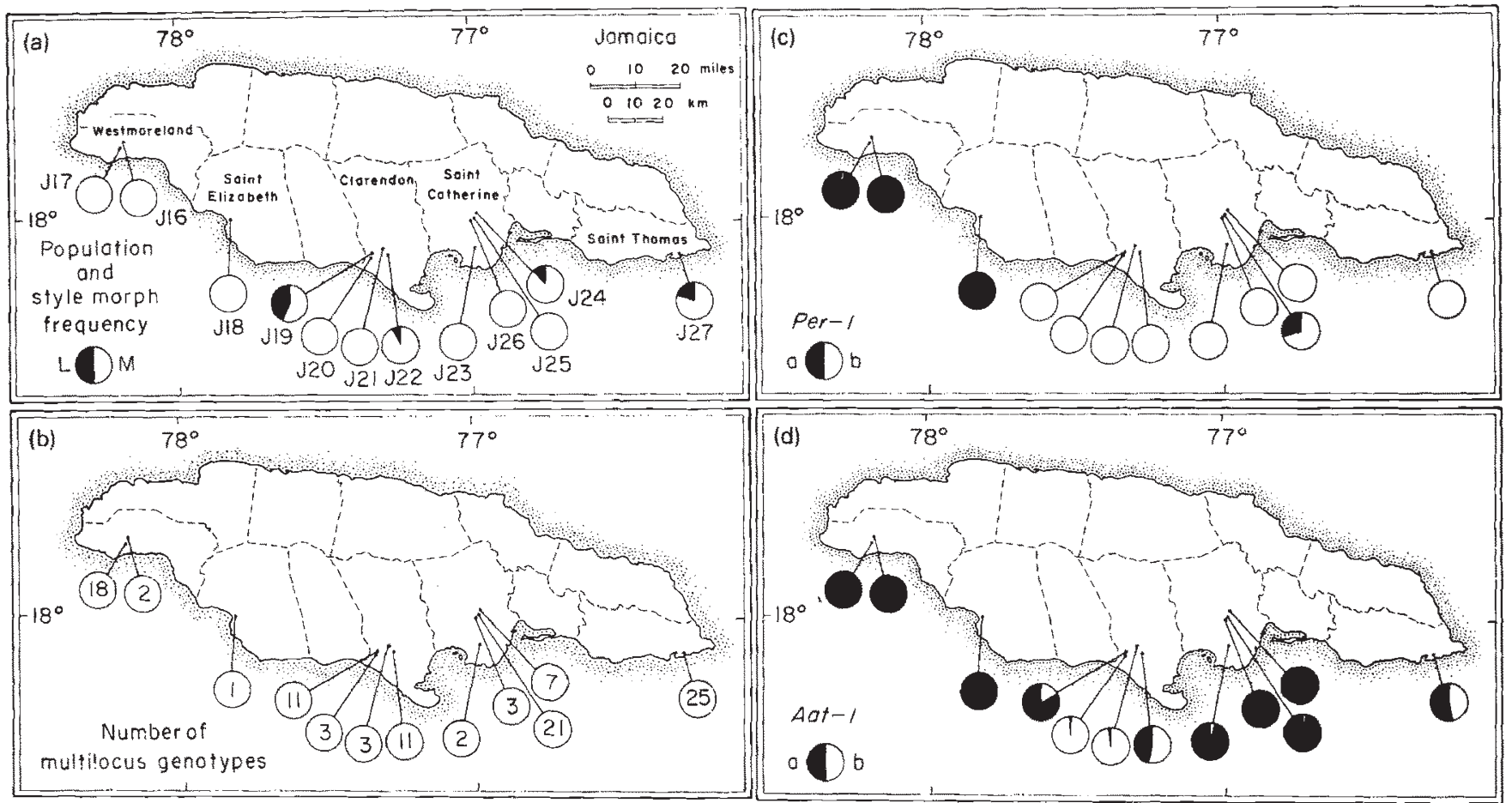

Fig. 1 Distribution of 12 populations of Eichhornia paniculata sampled from Jamaica. (a) Style morph frequencies (L - long; $\mathrm{M}-$ mid). (b) Number of multilocus genotypes. (c) Frequency of alleles at PER-I. (d) Frequency of alleles at $A A T-1$.

\begin{tabular}{|c|c|c|c|c|c|}
\hline Population & Locality & $\begin{array}{l}\text { Morph } \\
\text { structure* }\end{array}$ & $\begin{array}{l}\text { Population } \\
\text { * size }\end{array}$ & $\begin{array}{l}\text { Families } \\
\text { sampled }\end{array}$ & $\begin{array}{l}\text { Progeny } \\
\text { assayed }\end{array}$ \\
\hline $\mathrm{J} 16$ & George's Plain, Westmoreland & $M$ & 48 & 23 & 72 \\
\hline $\mathrm{J} 17$ & Meylersfield, Westmoreland & $\mathrm{M}$ & 2000 & 25 & 114 \\
\hline $\mathrm{J} 18$ & Pondside, St Elizabeth & M & 800 & 25 & 151 \\
\hline J19 & Milk River, Clarendon & D & 17 & 13 & 129 \\
\hline $\mathbf{J} 20$ & Pridees, Clarendon & M & 32 & 25 & 138 \\
\hline $\mathrm{J} 21$ & Rhymesbury, Clarendon & M & 222 & 25 & 91 \\
\hline $\mathrm{J} 22$ & Osborne, Clarendon & D & 19 & 11 & 57 \\
\hline $\mathrm{J} 23$ & Church Pen, St Catherine & $M$ & 5 & 5 & 36 \\
\hline $\mathrm{J} 24$ & Angels, St Catherine & $\mathrm{D}$ & 28 & 19 & 66 \\
\hline $\mathrm{J} 25$ & Spanish Town 1, St Catherine & $\mathrm{M}$ & 265 & 25 & 154 \\
\hline $\mathrm{J} 26$ & Spanish Town 2, St Catherine & M & 50 & 25 & 127 \\
\hline J27 & Old Pera, St Thomas & $\mathrm{D}$ & 1000 & 25 & 172 \\
\hline
\end{tabular}

Table 1 Location, morph structure, population size and the number of families sampled and individuals assayed for isozyme variation in 12 populations of Eichhornia paniculata from Jamaica

${ }^{*} \mathrm{D}=$ Dimorphic, $\mathrm{M}=$ monomorphic.

alleles. This can be seen by inspection of the allele frequency data for polymorphic loci given in the appendix. Allele frequencies were very similar in a comparable analysis (data not shown) using inferred maternal genotypes. The mean frequency of the most common allele for the six loci, within each population, was 0.92 . Because of low levels of polymorphism and uneven allele frequencies, populations of $E$. paniculata in Jamaica contained small numbers of multilocus genotypes (Fig. 1b, mean: 8.9 , range: $1-25$ ). Coeffi- cients of disequilibrium $\left(D_{A B}\right)$ were calculated for 16 pairs of loci from six populations (Table 3). Of these, six associations were statistically significant. This represents a significant level of disequilibrium since, by chance alone, one of the $16 D_{A B}$ values would be expected to be significant, assuming all values are independent. Furthermore, when a $D_{A B}$ value was significant for a given pair of loci in one population, values for the same pair were not always significant in other populations. Two populations exhibited no 
Table 2 Genetic variation at isozyme loci in 12 populations of Eichhornia paniculata from Jamaica. The percentage of loci that are polymorphic $(P)$ and observed and expected heterozygosity ( $H_{o}$ and $H_{e}$, respectively) are based on 27 loci scored. Allele richness per locus $\left(N_{a}\right)$ is calculated from polymorphic loci only. $t=$ Population estimate of outcrossing rate using the method of Ritland \& Jain (1981)

\begin{tabular}{lrllll}
\hline Population & \multicolumn{1}{l}{$P$} & $N_{a}$ & $H_{e}$ & $H_{o}$ & $t$ \\
\hline J16 & 3.7 & 2.0 & 0.016 & 0.000 & $0.169(0.11)$ \\
J17 & 11.1 & 2.7 & 0.038 & 0.011 & $0.100(0.03)$ \\
J18 & 0.0 & - & 0.000 & 0.000 & - \\
J19 & 11.1 & 2.0 & 0.030 & 0.005 & $0.014(0.03)$ \\
J20 & 0.0 & - & 0.001 & 0.001 & - \\
J21 & 0.0 & - & 0.001 & 0.000 & - \\
J22 & 7.4 & 2.5 & 0.037 & 0.007 & $0.130(0.07)$ \\
J23 & 0.0 & - & 0.001 & 0.001 & - \\
J24 & 7.4 & 2.0 & 0.029 & 0.016 & $0.093(0.10)$ \\
J25 & 11.1 & 2.3 & 0.043 & 0.017 & $0.224(0.08)$ \\
J26 & 3.7 & 2.0 & 0.018 & 0.001 & $0.002(0.03)$ \\
J27 & 11.1 & 2.0 & 0.055 & 0.016 & $0.203(0.07)$ \\
Mean & 5.5 & 2.2 & 0.022 & 0.006 & 0.117 \\
\hline
\end{tabular}

significant associations between loci $(\mathrm{J} 27, \mathrm{~J} 22)$ whereas in another two, all pairwise comparisons were significant (J19, J24).

\section{Mating system estimates}

The average frequency of heterozygotes among all loci sampled was 0.8 per cent. In 22 one-tailed tests all but one locus were significantly less heterozygous than expected for a random mating population. Although less extreme, a deficiency of heterozygotes, was also observed among the inferred maternal genotypes for most loci. These results indicate that Jamaican populations of $E$. paniculata are highly inbred. The high values of $f$ reiterate this finding (Table 4). Multilocus estimates of outcrossing rate $(t)$, ranged from 0.0 to 0.22 with a mean of $t=0.116$ (Table 2). Goodness-offit tests between the observed genotype frequencies and that expected for a given value of $t$, indicated deviations for $P G M-1$ in one population (J16). Outcrossing estimates for J16 were based solely on this locus, and therefore, should be interpreted with caution. Outcrossing rates were not significantly correlated with measures of genetic diversity (Spearman's rank correlation with: $H_{o}, \rho=0.53 ; P, \rho=0.34 ; N_{a}$, $\rho=-0.08$; critical correlation coefficient $P<0.05$, $N=8, \rho=0.71$ ).
Table 3 Gametic disequilibria between pairs of loci (Weir \& Cockerham, 1989) in six populations of Eichhornia paniculata from Jamaica. $A A T-1$ and $A A T-3$ were fixed for different alleles in all populations and are not included in the table

\begin{tabular}{lcccc}
\hline \multicolumn{4}{l}{ Locus } \\
\cline { 2 - 5 } Locus & $A A T-2$ & $P G M-1$ & $P G I-2$ & $P E R-1$ \\
\hline $\mathrm{J} 17$ & & & & \\
$A A T-3$ & - & - & 0.0098 & $-0.1140^{* *}$ \\
$P G M-1$ & - & - & - & -0.0111 \\
$\mathrm{~J} 19$ & & & & - \\
$A A T-1$ & $0.1227^{* *}$ & $-0.0724^{*}$ & - & - \\
$A A T-2$ & - & $-0.1219^{* *}$ & - & - \\
$\mathrm{J} 22$ & & & & - \\
$A A T-1$ & -0.0389 & 0.0401 & - & - \\
$A A T-2$ & - & 0.0257 & - & - \\
$\mathrm{J} 24$ & & & & - \\
$A A T-2$ & - & $0.1077^{* *}$ & - & - \\
$\mathrm{J} 25$ & & & & $-1049^{*}$ \\
$A A T-2$ & - & 0.0362 & - & - \\
$P G M-1$ & - & - & - & 0.0371 \\
$\mathrm{~J} 27$ & & & - & - \\
$A A T-1$ & -0.0367 & 0.0111 & - & - \\
$A A T-2$ & - & 0.0249 & - & - \\
\hline
\end{tabular}

${ }^{*} P<0.05,{ }^{* *} P<0.01$

\section{Population differentiation}

Jamaican populations of E. paniculata were highly differentiated from one another with respect to isozyme variation. Differences in allele frequencies among populations were statistically significant for all polymorphic loci $\left(A A T-1, \chi^{2}=203.95, P<0.01 ; A A T\right.$ $2, \quad \chi^{2}=301.97, \quad P<0.01 ; \quad A A T-3, \quad \chi^{2}=528.38$, $P<0.01 ; \quad P G M-1, \quad \chi^{2}=253.69, \quad P<0.01 ; \quad P G I-2$, $\chi^{2}=176.15, P<0.01 ;$ PER-1, $\left.\chi^{2}=528.87, P<0.01\right)$. Each test was also significant at the 5 per cent level based on the sequential Bonferroni test. Much of the differentiation results from the occurrence of unique alleles at $A A T-3 a, P G M-1 c$ and $P G I-2 a$ in populations $\mathrm{J} 16, \mathrm{~J} 17$ and $\mathrm{J} 18$ at the west end of the island. In addition, a fast allele at the PER-1a locus occurred at moderate frequency in population $\mathrm{J} 25$, but was absent from all remaining eastern populations (Fig. 1c,d).

Despite differences between populations at polymorphic loci, the mean genetic identity among all populations was high $(I=0.932)$ because of the relatively large number of monomorphic loci that each population has in common. Similarity among populations based on Nei's genetic distance is presented as a dendrogram in Fig. 2. The two western populations, 


\begin{tabular}{lllll}
\hline Locus & $F$ & $\phi$ & $f$ & $G_{S T}$ \\
\hline$A A T-1$ & $0.917(0.052)$ & $0.732(0.190)$ & $0.708(0.040)$ & 0.693 \\
$A A T-2$ & $0.861(0.073)$ & $0.718(0.133)$ & $0.490(0.082)$ & 0.749 \\
$A A T-3$ & $0.966(0.056)$ & $0.801(0.328)$ & $0.641(0.188)$ & 0.811 \\
$P G M-1$ & $0.857(0.071)$ & $0.493(0.117)$ & $0.711(0.122)$ & 0.499 \\
$P G I-2$ & $0.881(0.428)$ & $0.323(0.158)$ & $0.671(0.326)$ & 0.167 \\
$P E R-1$ & $0.972(0.033)$ & $0.899(0.121)$ & $0.770(0.051)$ & 0.912 \\
All loci & $0.896(0.003)$ & $0.692(0.05)$ & $0.661(0.01)$ & $0.704(0.07)$ \\
\hline
\end{tabular}

Table 4 Population differentiation among 12 populations of Eichhornia paniculata from Jamaica based on $F$ coefficients of progeny and gene diversity statistics. $F$ coefficients for each polymorphic locus were estimated using Weir \& Cockerham (1984). Standard deviations (in parentheses) were estimated by jack-knifing over populations for each locus
$\mathrm{J} 16$ and $\mathrm{J} 17$, are least similar to the remaining populations while J18, their nearest neighbour, was intermediate. Gene diversity measures also indicate strong between-population heterogeneity (Table 4). The level of population differentiation, $G_{S T}$, is homogeneous across loci, and overall, accounts for 70 per cent of the total gene diversity. Similarly, values of $\phi$, an alternate measure of genetic differentiation, indicate that most of the isozyme variation in $E$. paniculata is distributed among populations (Table 4).

\section{Spatial patterns}

There was a positive association between the genetic distance and the minimum geographical distance between populations $\left(K_{c}=170, \quad P=0.013\right)$. The correlation was particularly strong for populations separated by short to medium distances (up to $125 \mathrm{~km}$ ) but became weaker beyond this distance. The average autocorrelation for each distance class overall, and for the subset of significant correlograms, showed a positive correlation at near distances, up to $85 \mathrm{~km}$, and moderate negative autocorrelation beyond (Table 5).

Spatial autocorrelation analysis also revealed that variation at individual isozyme loci was non-randomly distributed. All alleles at polymorphic loci, except $P G M-1 b$, showed significant spatial structure between populations at one or more distance classes (Table 5). In total, 11 of 32 coefficients were significant at $P<0.05$. An overall significance test was conducted for each correlogram using a Bonferroni procedure (Oden, 1984). By this criterion, only three out of seven correlograms ( $A A T-1 a, A A T-3 a, P E R-1 a)$ were significant at $P<0.05$. Two contrasting patterns were evident among correlograms. For example, $P E R-1 a$ and $A A T$ $3 a$ varied monotonically beginning with positive autocorrelations between populations separated by small distances and ending with negative autocorrelations between most distant populations. In contrast, autocorrelations for $A A T-1 a$ decreased with increasing distance up to intermediate distances, but beyond this distance they increased. While the remaining correlo-

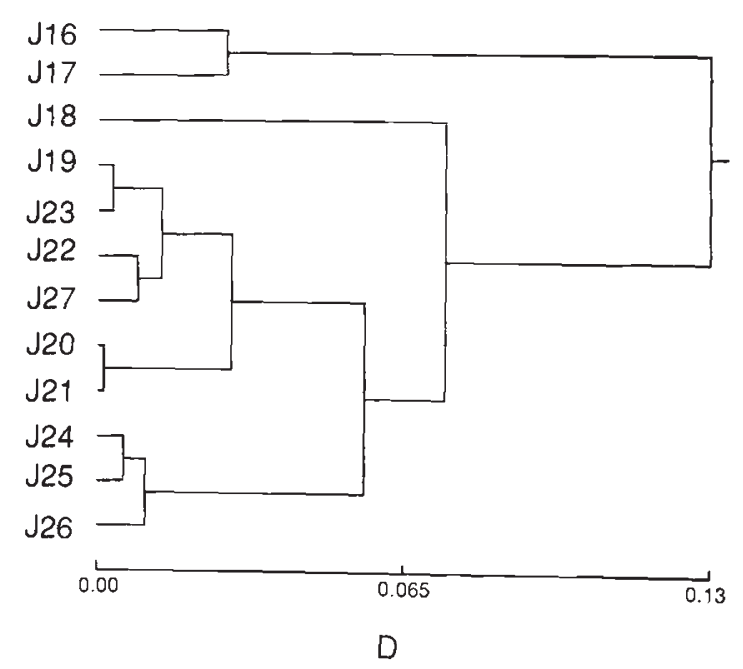

Fig. 2 Dendrogram summarizing the relationships between 12 populations of Eichhornia paniculata from Jamaica, based on Nei's measure of genetic distance.

grams were non-significant, each could be assigned to one of these two patterns. Allele frequency surfaces were significantly correlated $(P<0.05)$ in four of 21 possible pairs $(A A T-1-A A T-2, P G M-1 a-A A T-2, A A T-$ 3-PER-1, PGI-2-PGM-1b). Three involved at least one locus with a significant spatial correlogram. As with the correlograms, the pairs represent one of two types of surface, distinguishable by the degree of correlation at the largest distance.

\section{Discussion}

Our survey of isozyme variation in Eichhornia paniculata from Jamaica revealed low levels of polymorphism, allelic diversity and heterozygosity and a high degree of genetic differentiation among populations. This result is in accord with an earlier investigation of five populations sampled from the central region of the island (Glover \& Barrett, 1987). Collectively, the two studies demonstrate that Jamaican populations of $E$. paniculata are less variable than their mainland counterparts in northeastern Brazil. This finding is 
Table 5 Spatial autocorrelation coefficients (Moran's $I$ ) for allele frequencies at polymorphic loci among 12 populations of Eichhornia paniculata from Jamaica. Distance classes identified by upper boundaries

\begin{tabular}{llllll}
\hline \multirow{7}{*}{ Distance class $(\mathrm{km})$} \\
\cline { 2 - 6 } Allele & 30.3 & \multicolumn{1}{l}{39.1} & 85.3 & 124.6 & 198.0 \\
\hline AAT-1a & $0.60^{* *}$ & $-0.73^{* *}$ & -0.25 & -0.22 & 0.23 \\
AAT $-2 a$ & $0.53^{* *}$ & -0.51 & -0.20 & -0.49 & 0.34 \\
AAT-3a & $0.43^{* *}$ & 0.18 & 0.03 & $-0.53^{* *}$ & $-0.75^{* *}$ \\
PGM-1a & 0.10 & -0.25 & -0.16 & -0.34 & -0.30 \\
PGM-1b & 0.33 & -0.11 & -0.20 & $-0.64^{*}$ & -0.27 \\
PGI-2a & 0.01 & 0.29 & 0.07 & $-0.66^{* *}$ & $-0.85^{* *}$ \\
PER-1a & $0.49^{* *}$ & 0.11 & 0.02 & $-0.36^{*}$ & $-0.43^{*}$ \\
Mean & 0.36 & -0.15 & -0.10 & -0.46 & -0.29 \\
\hline
\end{tabular}

${ }^{*} P<0.05,{ }^{* *} P<0.01$.

consistent with the theoretical predictions of Wright's continent-island model of population genetic structure in small, isolated populations (Wright, 1940), and limited empirical data on genetic variation in continental and island populations of plants (reviewed in Barrett \& Husband, 1990a).

Comparisons of data on allelic diversity in northeastern Brazil and Jamaica indicate that 62 per cent of the alleles represented in mainland populations occur in Jamaica $(N=18$ and 17 populations in northeastern Brazil and Jamaica, respectively; Glover \& Barrett, 1987; B. C. Husband \& S. C. H. Barrett, unpublished data). Furthermore, the proportion of loci that are polymorphic in northeastern Brazil is $P=0.62$ compared with $P=0.22$ in Jamaica. This overall reduction in genetic diversity probably results from genetic bottleneck(s) associated with long-distance dispersal and limited opportunities for subsequent gene flow owing to island isolation. While the allelic diversity of Jamaican populations is substantially reduced in comparison with populations in northeastern Brazil, three alleles that occur in the island have not been detected in northeastern Brazil (AAT-3a, PGM-1c, PGI-2a). In addition, several alleles uncommon on the mainland ( $A A T-2 b, A A T-3 c, P G M-1 a$ ) occur at high frequencies among Jamaican populations. These patterns are consistent with founder effects and suggest that stochastic forces play a major role in influencing patterns of genetic variation in island populations.

Stochastic forces also appear to have been important in structuring patterns of genetic diversity within and among Jamaican populations following island colonization. Several features of the population biology of $E$. paniculata enhance opportunities for the occurrence of random genetic drift. Populations fluctuate dramatically in size, but are usually quite small (Table 1) and short-lived (Barrett et al., 1989). Furthermore, populations experience high levels of inbreeding (Table 2) and individuals display large variation in reproductive output owing to high phenotypic plasticity (Barrett, 1985). These factors all reduce effective population size allowing drift to occur (Crawford, 1984; Heywood, 1986). Allele frequencies at polymorphic loci were highly asymmetrical in most populations with the most frequent allele averaging 0.92 (range: $0.51-1.00$ ). In addition, populations contained relatively small numbers of multilocus genotypes with one or two different genotypes dominating within most populations. These patterns are consistent with the occurrence of a high degree of stochastic variation at neutral loci. Local populations appear to be founded by a small number of individuals and restricted gene flow and inbreeding acts to preserve particular allelic combinations. Such effects will cause large imbalances in allele frequencies, often among neighbouring populations, and reduce the potential number of multilocus genotypes that can occur within populations. The ephemeral nature of $E$. paniculata populations in Jamaica also makes them particularly susceptible to the stochastic loss of genetic variation.

Colonization of geographically isolated areas is often associated with shifts in the mating system towards increased levels of self-fertilization (Baker, 1955; Lloyd, 1980; Brown \& Burdon, 1987). This pattern is consistent with the hypothesis that selffertilizing variants are at a selective advantage at low density or where pollinators are unreliable or absent. While populations of $E$. paniculata in northeastern Brazil are generally highly outcrossed (mean $t=0.726$, range $0.25-0.96, N=21$ populations; Barrett \& Husband, 1990b) those on the island of Jamaica experience high levels of self-fertilization (Table 2). The predominance of self-pollinating variants of $E$. paniculata in Jamaica (see Fig. 3 in Barrett et al., 1989) undoubtedly results from the reproductive assurance from which these forms benefit in colony establishment following long-distance dispersal.

The multilocus outcrossing rates reported here for eight populations are significantly lower than estimates given in Glover \& Barrett (1987) for three dimorphic Jamaican populations $(\mathrm{J} 12, t=0.47 ; \mathrm{J} 14, t=0.29 ; \mathrm{J} 15$, $t=0.68$; see their table 1 ). This disparity results from differences in the methods of sampling employed in the two studies. In the previous investigation a small number of families were used and $t$ values were inflated owing to over-representation of families from the $\mathrm{L}$ morph in samples. More detailed investigation of the patterns of outcrossing in the $\mathrm{L}$ and $\mathrm{M}$ morphs have 
demonstrated large differences between the two in outcrossing rates in three Jamaican populations (mean $t=0.82$ and 0.12 for the $\mathrm{L}$ and $\mathrm{M}$ morphs, respectively; Barrett et al., 1989). In the present study, random samples were obtained from populations and since the $M$ morph predominated in all but one, estimates were reduced in comparison to the Glover and Barrett study. Clearly, caution is required in interpreting the biological significance of estimates of the average outcrossing rate for populations with mating system polymorphisms, particularly those involving discrete selfing and outcrossing morphs.

Jamaican populations of E. paniculata display a high degree of genetic differentiation, a result expected for predominantly inbreeding populations (Brown, 1979). Based on the 12 populations examined in this study, 70 per cent of the total isozyme diversity on the island is distributed among populations $\left(G_{S T}=0.70\right)$. This value is substantially higher than reported for the five populations examined by Glover \& Barrett (1987) from the central part of the island $\left(G_{S T}=0.57\right)$, and is also higher than the average value from a survey of 39 predominantly selfing species $\left(G_{S T}=0.52\right)$ conducted by Loveless \& Hamrick (1984). The higher $G_{S T}$ value obtained in the present study reflects more extensive sampling and inclusion of populations from the west end of the island that are highly differentiated from the remaining populations. This suggests that the high $G_{S T}$ value obtained is not solely the result of the mating system of populations, but also reflects the historical influence of colonization to the island.

Results from the spatial analyses of allele frequencies support the idea that historical factors, related to the initial colonization of Jamaica, contribute to the high levels of population differentiation observed. The dendrogram based on genetic distances indicates that populations in the west are electrophoretically distinct from the remaining populations on the island. This is primarily due to the presence of three unique alleles in western populations and large differences in allele frequencies at other polymorphic loci. Populations from the west of the island are also genetically differentiated from remaining populations in several floral and life history traits (see Barrett, 1985). These patterns and the positive autocorrelations between neighbouring populations indicate that the distribution of genetic variation among Jamaican populations is spatially autocorrelated. Spatial heterogeneity of this type is unlikely to be generated by drift alone (see Sokal \& Wartenberg, 1983), but may result from any one of three possible models of population structure. A correlation among neighbouring populations would be expected if (1) populations, which are stable in size, experience regular migration between neighbouring populations (stepping stone model), (2) selection for different genotypes occurs in a spatially heterogeneous environment, and (3) separate colonization events to different parts of the island occur from migrants differing in allele frequency at several loci. The likelihood of these models can be inferred by comparing the allele frequency surfaces and spatial correlograms at polymorphic loci (Sokal \& Menozzi, 1982; Sokal et al., 1989).

Patterns of genetic variation among Jamaican populations are not in accord with those predicted by the stepping stone model. While populations are distributed in a linear fashion and a relationship exists between genetic and geographical distance, major discontinuities in allele frequency occur particularly between population groups from the west and central parts of the island. These patterns are reflected in the spatial correlograms which fail to show a gradual decline in correlation with distance as would be expected in the stepping stone model (Sokal \& Wartenberg, 1983). Furthermore, if the three western populations are excluded from the analysis of relationships between genetic and geographical distance, no significant correlation occurs $\left(K_{c}=31, P=0.15\right)$. This result was also found by Glover \& Barrett (1987) in their study of populations from the central region of the island.

The spatial autocorrelation analysis indicates two classes of correlograms, with similar allele surfaces within each class. If the spatial autocorrelation of isozyme variation is associated with selection, the environment must have affected alleles at different loci similarly. Multilocus associations can arise when selection acts on coadapted complexes of alleles (Allard et al., 1972), or when alleles at neutral isozyme loci hitchhike with selected loci (Hedrick \& Holden, 1979). The latter is likely in predominant inbreeders because of the slow decay of gametic disequilibrium among loci. Although significant levels of gametic disequilibrium were observed in some populations of $E$. paniculata, the intensity of inbreeding may be insufficient to maintain high levels of disequilibrium in all populations. While populations exhibited high self-fertilization, outcrossing levels were appreciable in many populations (mean $t=0.116$ ). With this mating system, it would take less than about 12 generations for multilocus disequilibria between unlinked loci to decay by one half (Weir et al., 1972). The significant $D_{A B}$ values observed in four populations of $E$. paniculata are more likely to be associated with the colonizing life history of the species. Chance associations between loci frequently arise in small, ephemeral populations leading to significant gametic disequilibrium (Golding \& Strobeck, 1980). If disequilibrium is transient, because of low 
levels of outcrossing and/or short-lived populations, it would be unlikely that selection could produce the patterns of allele frequency at different loci that were observed in our study. If this is true, the isozyme differentiation between populations from the west and those from the remainder of the island is more likely to have resulted from separate colonization events involving migrants with different allele frequencies.

Separate colonization events by $E$. paniculata to different parts of Jamaica would result in correlated differences at all neutral genes among founding populations. This may explain the parallel patterns and spatial discontinuities in allele frequencies observed among polymorphic loci. The occurrence of two classes of correlograms in the spatial autocorrelation analysis is not inconsistent with a hypothesis of multiple colonization events. Migrants to the west versus those to the remaining parts of the island may share common alleles at some loci $(A A T-1, A A T-2$ and $P G M-1 a)$ but differ at others (AAT-3, PGI-2, PGM-1 and $P E R-1$ ). While these historical processes can account for the observed patterns of variation in Jamaica, like all hypotheses involving evolutionary history, they are notoriously difficult to prove. Moreover, the relatively small number of populations of $E$. paniculata in Jamaica and low levels of isozyme polymorphism make it particularly difficult to infer patterns of island colonization with any certainty.

\section{Acknowledgements}

We thank Martin Morgan, Jan Conn and Jascintha Simpson for field assistance, Bruce Weir for providing the $F$ statistics and linkage programmes, William Cole for help with the analyses, Brian Epperson and Ruth Harding for suggestions concerning spatial autocorrelation techniques and the Natural Sciences and Engineering Research Council of Canada for financial support.

\section{References}

ALLARD, R. W., BABBEL, G. R., CLEGG, M. T. AND KAHLER, A. L. 1972. Evidence for coadaptation in Avena barbata. Proc. Natl Acad. Sci., 69, 3043-3048.

BAKER, H. G. 1955. Self-compatibility and establishment after 'long distance' dispersal. Evolution, 9, 347-349.

BARBUJANI, G. 1987. Diversity of some gene frequencies in European and Asian populations III. Spatial correlogram analysis. Ann. Hum. Genet., 51, 345-353.

BARRETT, S. C. H. 1985. Floral trimorphism and monomorphism in continental and island populations of Eichhornia paniculata (Spreng.) Solms. (Pontederiaceae). Biol. J. Linn. Soc., 25, 41-60.

BARRETT, S. C. H. 1988. Evolution of breeding systems in
Eichhornia (Pontederiaceae): a review. Ann. Miss. Bot. Gard., 75, 741-760.

BARRETT, s. C. H. AND HUSBAND, B. C. $1990 \mathrm{a}$. The genetics of plant migration and colonization. In: Plant Population Genetics, Breeding, and Genetic Resources, Brown, A. H. D., Clegg, M. T., Kahler, A. L. and Weir, B. S. (eds), Sinauer Ass. Inc., Sunderland, Massachussetts, pp. 254-277.

BARRETT, S. C. H. AND HUSBAND, B. C. 1990b. Variation in outcrossing rates in Eichhornia paniculata: the role of demographic and reproductive factors. J. Species Biol. 5, 41-56.

BARRETT, S. C. H., MORGAN, M. T. AND HUSBAND, B. C. 1989. Dissolution of a complex genetic polymorphism: the evolution of self-fertilization in tristylous Eichhornia paniculata (Pontederiaceae). Evolution, 43, 1398-1416.

BARRETT, S. C. H. AND RICHARDSON, B. J. 1986. Genetic attributes of invading species. In: Ecology of Biological Invasions: An Australian Perspective, Groves, R. H. and Burdon, J. J. (eds), Australian Academy of Science, Canberra, pp. 21-33.

BROWN, A. H. D. 1979. Enzyme polymorphisms in plant populations. Theor. Pop. Biol., 15, 1-42.

BRowN, A. H. D. 1983. Multilocus organization of plant populations. In: Population Biology and Evolution, Wohrmann, K. and Loescheke, V. (eds), Springer-Verlag, Berlin, pp. 159-169.

BROWN, A. H. D. AND ALLARD, R. W. 1970. Estimation of the mating system in open-pollinated maize populations using isozyme polymorphisms. Genetics, 66, 133-145.

BROWN, A. H. D. AND BURDON, J. J. 1987. Mating systems and colonising success in plants. In: Colonization, Succession and Stability, British Ecol. Soc. Symp. No 26, Gray, A. J., Crawley, M. J., Edwards, P. J. (eds), Blackwell Scientific Publications, Oxford, pp. 115-132.

CLIFFORD, A. D. AND ORD, J. K. 1973. Spatial Autocorrelation, Pion, London.

COCKERHAM, C. C. 1969. Variance of gene frequencies. Evolution, 23, 72-84.

COCKERHAM, c. c. 1973. Analyses of gene frequencies. Genetics, 74, 679-700.

CRAWFORD, T. J. 1984. What is a population? In: Evolutionary Ecology, Shorrocks, B. (ed.), Blackwell Scientific Publications, Oxford, pp. 135-173.

DIETZ, E. J. 1983. Permutation tests for association between two distance matrices. Syst. Zool., 32, 21-26.

GABRIEL, K. R. AND SOKAL, R. R. 1969. A new statistical approach to geographic variation analysis. Syst. Zool., 18, 259-270.

GLOVER, D. E. AND BARRETT, s. C. H. 1987. Genetic variation in continental and island populations of Eichhornia paniculata (Pontederiaceae). Heredity, 59, 7-17.

GOLDING, G. B. AND STROBECK, C. 1980. Linkage disequilibrium in a finite population that is partially selfing. Genetics, 94, 777-789.

GOLENBERG, E. 1989. Migration patterns and the development of multilocus associations in a selfing annual, Triticum dicoccoides. Evolution, 43, 595-606.

HEDRICK, P. W. AND HOLDEN, L. 1979. Hitchhiking: an alternative to coadaptation for the barley and slender wild oat 
examples. Heredity, 43, 79-86.

HEYWOOD, J. s. 1986. The effect of plant size variation on genetic drift in populations of annuals. Am. Nat., 127, 851-861.

HOLM, s. 1979. A simple sequentially rejective multiple test procedure. Scand. J. Stat., 6, 65-70.

LLOYD, D. G. 1980. Demographic factors and mating patterns in angiosperms. In: Demography and Evolution of Plant Populations, Solbrig, O. T. (ed.), Blackwell Scientific Publications, Oxford, pp. 67-88.

LOVELESS, M. D. AND HAMRICK, J. L. 1984. Ecological determinants of genetic structure in plant populations. Ann. Rev. Ecol. Syst., 15, 65-95.

MORAN, G. F. AND MARSHALL, D. R. 1978. Allozyme uniformity within and variation between races of the colonizing species Xanthium strumarium L. (Noogora Burr). Aust. J. Biol. Sci., 31, 283-291.

NEI, M. 1973. Analysis of gene diversity in subdivided populations. Proc. Natl Acad. Sci. USA, 70, 3321-3323.

NEI, M. 1975. Molecular Population Genetics and Evolution, North-Holland, New York.

NEI, M. 1978. Estimation of average heterozygosity and genetic distance from a small number of individuals. Genetics, 89, 583-590.

NOVAK, S. AND MACK, R. N. 1989. Electrophoretic variation in native range populations of Bromus tectorum L. (cheatgrass): evidence for genetic bottlenecks following introduction. Ann. J. Bot., 76, abstract no. 400.

ODEN, N. L. 1984. Assessing the significance of a spatial correlogram. Geogr. Anal., 16, 1-16.

RITLAND, K. 1989. A series of FORTRAN computer programs for estimating plant mating systems. J. Hered, 81, 235-237.

RITLAND K. AND JAIN, S. K. 1981. A model for the estimation of outcrossing rate and gene frequencies using $n$ independent loci. Heredity, 47, 35-52.

SOKAL, R. R. 1979. Ecological parameters inferred from spatial correlograms. In: Contemporary Quantitative Ecology and Related Ecometrics, Patil, G. N. and Rosenzweig, M. L. (eds), International Co-operative
Publishing House, Fairland, Maryland, pp. 167-196.

SOKAL, R. R., JACOUEZ, G. M. AND WOOTEN, M. C. 1989. Spatial autocorrelation analysis of migration and selection. Genetics, 121, 845-855.

SOKAL, R. R. AND MENOZZI, P. 1982. Spatial autocorrelations of HLA frequencies in Europe support demic diffusion of early farmers. Am. Nat., 1 19, 1-17.

SOKAL, R. R. AND ODEN, N. L. 1978. Spatial autocorrelation in biology I. Methodology. Biol. J. Linn. Soc., 10, 199-228.

SOKAL, R. R., ODEN, N. L. AND BARKER, J. S. F. 1987. Spatial structure in Drosophila buzzatii populations: simple and directional spatial autocorrelation. Am. Nat., 129, 122-142.

SOKAL, R. R. AND WARTENBERG, D. E. 1983. A test of spatial autocorrelation analysis using an isolation-by-distance model. Genetics, 105, 219-237.

SOLTIS, D. E., HAUfLER, C. H., DARROW, D. C. AND GASTONY, G. J. 1983. Starch gel electrophoresis of ferns: a compilation of grinding buffers, gel and electrode buffers, and staining schedules. Am. Fern J., 73, 9-27.

TAKAHATA, N. AND NEI, M. 1984. $F_{S T}$ and $G_{S T}$ statistics in the finite island model. Genetics, 106, 501-503.

TOPPINGS, P. 1989. The significance of inbreeding depression to the evolution of self-fertilization in Eichhornia paniculata (Spreng.) Solms. (Pontederiaceae). M.Sc Thesis, University of Toronto.

WEIR, B. S., ALlARD, R. W. AND KaHLER, A. L. 1972. Analysis of complex allozyme polymorphisms in a barley population Genetics, 72, 505-523.

WEIR, B. S. AND COCKERHAM, C. C. 1984 . Estimating $F$-statistics for the analysis of population structure. Evolution, $\mathbf{3 8}$, $1358-1370$.

WEIR, B. S. AND COCKerHAM, C. c. 1989. Complete charac terization of disequilibrium at two loci. In: Mathematical Evolutionary Theory, Feldman, M. W. (ed.), Princeton University Press, Princeton, pp. 86-110.

WRIGHT, s. 1940 . Breeding structure of populations in relation to speciation. Amer. Nat., 74, 232-248.

WRIGHT, s. 1951. The genetical structure of populations. Ann. Eugen., 15, 313-354.

Appendix Allele frequencies at six polymorphic isozyme loci surveyed in 12 populations of Eichhornia paniculata from Jamaica. Loci are numbered in ascending order, starting with the most anodally migrating; alleles are lettered starting with the most anodal. Sample size $(N)$ is given for each locus-population combination

\begin{tabular}{|c|c|c|c|c|c|c|c|c|c|c|c|c|c|}
\hline Locus & & $\mathrm{J} 16$ & $\mathrm{~J} 17$ & $\mathrm{~J} 18$ & $\mathrm{~J} 19$ & $\mathrm{~J} 20$ & $\mathrm{~J} 21$ & $\mathrm{~J} 22$ & $\mathrm{~J} 23$ & $\mathrm{~J} 24$ & $\mathrm{~J} 25$ & $\mathrm{~J} 26$ & $\mathrm{~J} 27$ \\
\hline \multirow{3}{*}{$\begin{array}{rl}A A T I & a \\
b & \\
N\end{array}$} & & 1.00 & 1.00 & 1.00 & 0.83 & 0.01 & 0.02 & 0.47 & 0.97 & 1.00 & 0.98 & 1.00 & 0.54 \\
\hline & $b$ & 0.00 & 0.00 & 0.00 & 0.17 & 0.99 & 0.98 & 0.53 & 0.03 & 0.00 & 0.02 & 0.00 & 0.46 \\
\hline & $N$ & 72 & 114 & 151 & 129 & 138 & 91 & 57 & 36 & 66 & 154 & 127 & 172 \\
\hline \multirow{3}{*}{$A A T 2$} & $a$ & 0.00 & 0.00 & 1.00 & 0.90 & 1.00 & 1.00 & 0.96 & 1.00 & 0.23 & 0.25 & 0.00 & 0.59 \\
\hline & $b$ & 1.00 & 1.00 & 0.00 & 0.10 & 0.00 & 0.00 & 0.04 & 0.00 & 0.77 & 0.75 & 1.00 & 0.41 \\
\hline & $N$ & 72 & 115 & 148 & 130 & 139 & 90 & 57 & 36 & 66 & 154 & 128 & 172 \\
\hline \multirow{3}{*}{$A A T 3$} & $a$ & 1.00 & 0.51 & 0.00 & 0.00 & 0.00 & 0.00 & 0.00 & 0.00 & 0.00 & 0.00 & 0.00 & 0.00 \\
\hline & $b$ & 0.00 & 0.49 & 1.00 & 1.00 & 1.00 & 1.00 & 1.00 & 1.00 & 1.00 & 1.00 & 1.00 & 1.00 \\
\hline & $N$ & 71 & 116 & 152 & 130 & $140^{\circ}$ & 92 & 59 & 35 & 67 & 155 & 126 & 172 \\
\hline \multirow{4}{*}{ PGMI } & $a$ & 0.31 & 0.89 & 0.00 & 0.25 & 0.01 & 0.00 & 0.29 & 0.00 & 0.68 & 0.79 & 0.41 & 0.51 \\
\hline & $b$ & 0.00 & 0.04 & 1.00 & 0.75 & 0.99 & 1.00 & 0.71 & 1.00 & 0.32 & 0.21 & 0.59 & 0.49 \\
\hline & $c$ & 0.69 & 0.07 & 0.00 & 0.00 & 0.00 & 0.00 & 0.00 & 0.00 & 0.00 & 0.00 & 0.00 & 0.00 \\
\hline & $N$ & 68 & 116 & 150 & 130 & 130 & 90 & 56 & 33 & 64 & 155 & 127 & 170 \\
\hline \multirow[t]{3}{*}{ PGI2 } & $a$ & 0.00 & 0.18 & 0.00 & 0.00 & 0.00 & 0.00 & 0.00 & 0.00 & 0.00 & 0.00 & 0.00 & 0.00 \\
\hline & $b$ & 1.00 & 0.82 & 1.00 & 1.00 & 1.00 & 1.00 & 1.00 & 1.00 & 1.00 & 1.00 & 1.00 & 1.00 \\
\hline & $N$ & 71 & 117 & 152 & 130 & 141 & 93 & 59 & 36 & 67 & 154 & 128 & 171 \\
\hline \multirow{3}{*}{ PERI } & $a$ & 1.00 & 0.99 & 1.00 & 0.00 & 0.00 & 0.00 & 0.00 & 0.00 & 0.00 & 0.30 & 0.00 & 0.00 \\
\hline & $b$ & 0.00 & 0.01 & 0.00 & 1.00 & 1.00 & 1.00 & 1.00 & 1.00 & 1.00 & 0.70 & 1.00 & 1.00 \\
\hline & $N$ & 72 & 113 & 152 & 128 & 141 & 93 & 59 & 36 & 66 & 154 & 128 & 172 \\
\hline
\end{tabular}

